\title{
Prevalence of caries in intellectually impaired children at Sekolah Semangat Maju, Taiping, Perak, Malaysia
}

\author{
Sanjit Singh, Inne Suherna Sasmita*, Asty Samiaty Setiawan** \\ *Department of Pediatric Dentistry Faculty of Dentistry Universitas Padjadjaran \\ **Department of Public Health Faculty of Dentistry Universitas Padjadjaran
}

\section{ABSTRACT}

Dental caries also known as tooth decay is a disease where a bacterial process damages the hard tooth structure. The aim of conducting this research was to obtain the prevalence of caries in the intellectually impaired children in Sekolah Semangat Maju, Taiping, Perak, Malaysia. The research was a descriptive research that utilized the survey technique. The population of the research were the students aged 7-17 years old from class 1 to class 5 . The total sample for this research was 56 students. The students were examined for the presence of caries and the results were used to obtain the prevalence of caries in these subjects. The results from this study showed that the prevalence of caries based on the student's medical diagnose was $68.42 \%$ for autism students, $57.14 \%$ for cerebral palsy students, $91.67 \%$ for Down's syndrome students, $100.00 \%$ for mental retardation students and $42.86 \%$ for slow learner students. The conclusion from this research was that the overall prevalence of caries in intellectually impaired children at Sekolah Semangat Maju Taiping, Perak, Malaysia is $67.89 \%$.

Key words: Dental caries, prevalence of caries, intellectually impaired children

\section{INTRODUCTION}

Based on the report released by the Oral Health Division under the Ministry of Health Malaysia, it states that primary healthcare in Malaysia is the thrust of the Malaysian healthcare system and the country is signatory to the Alma Alta Declaration, 1978. One of the tenets that is embodied in the concept and philosophy of health in Malaysia is that health is a fundamental right of every Malaysian and every individual has the right to develop and lead a healthy life. ${ }^{1}$

The oral healthcare, which is a part of the healthcare system in Malaysia, has been divided into three major components, mainly the primary, specialist and community oral healthcare. Under the primary oral healthcare, various programmes had been developed for all groups of the population, including children. An example of one of these programmes includes the establishment of dental clinics in school nationwide since the early 1950s. More recently, these programmes have been expanded to cover for the disabled children through regular visits to the school by the staff from the local health establishment.

A handicapped person is defined as an individual who, because of a physical or mental disability, is at a disadvantage in performing one or more major life activities including communication, movement, employment, education, socialization 
and self care. ${ }^{2} \mathrm{~A}$ more recent definition according to The International Classification of Impairment, Disability and Handicap as given by WHO, defines handicap as a disadvantage for a given individual, resulting from an impairment or a disability, that limits or prevents the fulfilment of a role that is normal (depending on age, sex, and social and cultural factors) for that individual. ${ }^{3}$

A child who is handicapped intellectually would not be able to understand and appreciate the importance of oral hygiene. The lack of ability to carry out simple live functions can be observed in the child's daily activities, such as eating, bathing, cleaning, playing and even tooth brushing. ${ }^{4} \mathrm{~A}$ decrease in maintenance of oral hygiene would eventually lead to the development of dental caries. This presents as a more severe problem in children that have an additional physical disability. It affects their self-esteem and total well-being. ${ }^{5}$

Lack of care by parents or guardians to maintain an adequate level of oral hygiene in the intellectually impaired child presents a problem in the long run. Development of dental caries in a disabled child is generally more difficult to treat compared to their normal peers. ${ }^{6}$ As dental caries can lead to the dissolution and destruction of the tooth structure, restoring it in a handicapped child can be challenging. Anxiety or fear may add on to the child's reluctance in attending a dental clinic. These are some of the hurdles that are faced by caregivers and dentists in treating these individuals. ${ }^{7}$ Therefore, it is essential to prevent the development of dental caries amongst these children as early as possible through more aggressive preventive measures.

The World Oral Health Report states that dental caries is still a major oral health problem in most industrialized countries affecting $60-90 \%$ of schoolchildren and the vast majority of adults. ${ }^{8}$ Data from The Dental Epidemiological Survey in 1997 showed that the prevalence of caries amongst 6-year old children in Malaysia was $80.9 \% .{ }^{1}$ A similar study performed in 2004 amongst 16-year-old school children through out Malaysia showed that the prevalence of caries amongst these subjects was $75.5 \% .{ }^{9}$ These figures enables one to grasp the fact that dental caries is still a burden in terms of oral diseases within most regions throughout the world and even so in Malaysia.
Similar, but fewer surveys have been conducted to access the prevalence of dental caries among the intellectually impaired children. One such survey carried out in Hyderabad, India, showed that the prevalence of caries in the mentally challenged individuals was $56 \% .^{10}$

Since these groups of disabled children are generally scattered within the population, the author has considered in focusing on the students at Sekolah Semangat Maju in Taiping, Perak, Malaysia. The school caters for children as young as 6 years old to adults aged 25 years and above. Majority of the students at the school are those that attend the academic classes that cater for children aged 7-17 years old.

Like others within a society, intellectually impaired children are prone to developing dental caries as well. Hence, the author has taken an interest in determining the prevalence of dental caries amongst these subjects. As to date, there has been insufficient and lack of data regarding the prevalence of caries in intellectually impaired children within this location. Based on the background of the research above, the problem identified is what is the prevalence of caries in the intellectually impaired children at Sekolah Semangat Maju, Taiping, Perak, Malaysia.

Impairment can be classified into 3 main categories-intellectual, physical and sensory. The causes of intellectual impairment are numerous and for many children a cause for their disability may never be indentified. ${ }^{7}$ As defined by the American Association on Intellectual and Developmental Disabilities ${ }^{11}$ intellectual impairment is a disability characterized by significant limitations both in intellectual functioning and in adaptive behavior, which covers many everyday social and practical skills. This disability originates before the age of 18.

Intellectual functioning, also called intelligence, refers to general mental capacity, such as learning, reasoning, problem solving, and so on. ${ }^{11}$ On the other hand, adaptive skills or behaviour is defined as the ability to accomplish tasks demanded by society, personal responsibility and willingness to undertake such tasks and social responsibility and the ability to behave appropriately in terms of cultural expectations. ${ }^{4}$ An intellectually impaired children is diagnosed based on three criteria: an IQ below 70, limitations 
in adaptive behaviour and manifested before the age of $18 .{ }^{11}$

Approximately 25 per 1000 children in the world are affected by intellectual impairment, and the majority are males. These children are categorised into two broad groups as being either mentally retarded or having a learning difficulty. Besides these, intellectual impairment may also be present in several other conditions such as cerebral palsy, autism, microcephaly, severe infections, major trauma or some other syndromes. ${ }^{7}$ The intellectually impaired children exhibit delays in the development of their adaptive behaviours such as self-help and self-care skills. Hence, the daily activity such as maintaining good oral hygiene becomes compromised and this set back may give rise to dental caries formation.

Dental caries is a microbiologic disease of the teeth that results in localized dissolution and destruction of the calcified tissues. ${ }^{12}$ The main etiologic factors that cause dental caries are the causative agent (bacteria), environment (diet), host (teeth) and time. All these factors have to operate simultaneously in order for caries to occur. Once it present, a carious tooth will form a cavity over a period of time, and if not treated promptly, it would need to be extracted. The prevalence of caries can be defined as the number of cases of caries that were present in a specific population at a given point in time. ${ }^{13}$

Poor comprehension towards oral hygiene amongst these children and the lack of care by parents or guardians, places them at a higher risk of developing dental caries. It could be assumed that this group of subjects would suffer from a higher prevalence of caries.

\section{MATERIALS AND METHODS}

The research was a descriptive research using the survey technique. The location and population were selected based on purposive sampling. The survey was held at Sekolah Semangat Maju in Taiping, Perak, Malaysia. It was carried out from the $10^{\text {th }}$ to the $12^{\text {th }}$ of March 2009.

The population of this research were the intellectually impaired students of Sekolah Semangat Maju, Taiping, Perak who are from class 1 to class 5 . The sample size chosen was through total sampling.
Criteria of population: Children who have been diagnosed as intellectually impaired based on the three main criteria: Intelligence Quotient (IQ) of less than 70, Limitations in adaptive behaviour or skills, Manifest before the age of 18; Students age 7 to 17 years old; Students who are attending school during the survey period; and Parents or guardians of the student that have given permission through the informed consent.

Research procedure began with examination area was prepared and set-up for the survey. The student is guided and sat down by the class teacher. Student's data was filled into the survey form based on the student record. The student was instructed to open his or her mouth and teeth are examined, assisted by the class teacher. Student's teeth were examined for presence of dental caries. Student's dentition status was filled into the survey form. Examiner expressed gratitude and gave encouragement to the student or future dental visit. Class teacher guided the student back to the classroom.

The data collected from the survey was tabulated into tables. The total number of samples and the number of students that were suffering from dental caries is then gathered from these tables. These figures were then used to calculate the prevalence of caries.

\section{RESULTS}

The result of this research was the prevalence of caries in the intellectually impaired children from class 1 to class 5 of Sekolah Semangat Maju Taiping, Perak, Malaysia. Based on the survey that was conducted, the data was presented in the following tables as shown below. Table 1 show that the total number of samples that were examined for this research. Table 2 shows the distribution of students affected with caries according to their medical diagnose. Table 3 shows that out of the 56 students that were examined.

\section{DISCUSSION}

Patients with developmental, physical, medical or mental disabilities that prevent or limit routine daily oral health care are at an increased risk for the development of caries. ${ }^{14}$ Mentally or physically disabled individuals, whom are unable 
Table 1. Sample distribution of students examined from class 1 to class 5.

\begin{tabular}{lc}
\hline Medical diagnose & Total samples examined \\
\hline Autism & 19 \\
Cerebral palsy & 7 \\
Down's syndrome & 12 \\
Mental retardation & 4 \\
Slow learner & 14 \\
\hline \multicolumn{1}{c}{ Total } & $\mathbf{5 6}$ \\
\hline
\end{tabular}

Table 2. Distribution of students affected with caries.

\begin{tabular}{lccc}
\hline Medical diagnose & Samples & Caries & Prevalence (\%) \\
\hline Autism & 19 & 13 & 68,42 \\
Cerebral palsy & 7 & 4 & 57,14 \\
Down's syndrome & 12 & 11 & 91,67 \\
Mental retardation & 4 & 4 & 100,00 \\
Slow learner & 14 & 6 & 42,86 \\
\hline
\end{tabular}

Table 3. Prevalence of caries for students of Sekolah Semangat Maju, Taiping.

\begin{tabular}{ccc}
\hline Total samples & $\begin{array}{c}\text { Total samples with } \\
\text { caries }\end{array}$ & $\begin{array}{c}\text { Prevalence } \\
\text { of caries (\%) }\end{array}$ \\
\hline 56 & 38 & 67,86 \\
\hline
\end{tabular}

or unwilling to comply with dietary and oral hygiene instructions, are at an increased risk of developing caries. ${ }^{12}$ These facts explain that the students at this school can be considered as one of the high-risk groups for suffering from dental caries. Knowing which patients are at high risk for developing caries provides an opportunity to implement specific preventive strategies that may prevent the development of this disease.

Based on the results in Tab. 2, it is shown that the mentally retarded students have the highest prevalence of caries of $100 \%$. This is possible due to these groups of students falling under the severe or profound mental retardation classification. The mentally retarded individuals are segregated into a classification that relies on their educational and social prognosis. These individuals were classified with an IQ of 25 and below as being 'non-trainable'. ${ }^{2}$ Persons under this category may contribute partially to selfmaintenance under supervision or they might achieve very limited self-care and may require nursing care. Individual with such severe levels of mental retardation are unlikely to be able to live independently and will always depend inappropriately on others as a source of income and support for daily living. ${ }^{7}$

This is where parents or caregivers play an essential role in maintaining the oral hygiene of these individuals. Often, caregivers are not aware of the necessity of preventive oral care, and they may neglect to provide it for those for whom they are responsible. ${ }^{15}$

The second highest prevalence of caries involves the Down's syndrome students which is 91.67\%. This result is contradictory to the facts stated in previous studies. Children and young adults who have Down syndrome have fewer caries than people without this developmental disability. ${ }^{16}$ The lower prevalence of dental caries observed in previous studies was attributed to higher salivary $\mathrm{pH}$, bicarbonate levels and Streptococcus mutant counts, microdontia, hypodontia and spaced dentition, delayed eruption and shallow fissures in premolars and molars. ${ }^{17}$

However, the result obtained from this research showed the opposite of previous studies. This higher incidence of caries in Down syndrome children could be due to the lack of awareness about dental visits, irregular dietary habits, inadequate oral hygiene measures, easy availability of high sucrose-containing cheap food stuffs, parental neglect and lack of initiative towards prevention by caregivers. ${ }^{18}$ Oredugba ${ }^{17}$ in his research obtained similar results and concluded that the reasons for this may include the reduced manual dexterity of the participants, joint laxity (including the carpal joints) and the lack of comprehension of oral hygiene needs due to mental difficulties. Besides that, as these children grow older, the assistance received from parents and care-givers begins to reduce, because it is believed that an older child should not need help with tooth brushing.

The autistic students examined had a prevalence of caries of $68.42 \%$. Amongst the difficulties experienced are mostly when oral hygiene practice is prevented. The child's difficult behaviour, lack of communication and decreased intelligence are all factors associated with maintaining a proper oral hygiene practice in these subjects. ${ }^{2}$ Dental caries risk increases in patients who have a preference for soft, sticky, or sweet foods, damaging oral habits and difficulty 
brushing and flossing. Besides that, parents and guardians also tend to comfort or pacify these difficult children or even provide incentives or rewards with cariogenic foods and beverages. ${ }^{16}$

Generally, parents or caregivers are demotivated on practising regular oral hygiene practices for the children under their care when they are unsuccessful in communicating with the child. As we know, consuming fermentable carbohydrates and poor oral hygiene practice are amongst the factors responsible to the development of dental caries. Therefore, it shows that such negative practices together with the child's difficult behavior might be accountable for the presence of dental caries in the autistic students.

Cerebral palsy students are the next on the list with a prevalence of $57.14 \%$. It is a disorder of the central nervous system that may manifest as various types of dysfunction such as spasticity, athetosis, ataxia, rigidity or tremor. Most of the cerebral palsy children have a higher caries rate than normal children. ${ }^{6}$ This increase can be attributed to their inability to maintain good oral hygiene and their parents' tendency to indulge them with soft and cariogenic food. Other risk factors include mouth breathing, the effects of medication, enamel hypoplasia, and food pouching. ${ }^{16}$

Oral clearance of food particles and the avoidance of prolonged retention of food in the mouth is difficult for individuals with cerebral palsy because of the abnormal function of the tongue, lips, and cheeks and the presence of an abnormal swallowing pattern. Because of the difficulties of mastication and deglutition, patients with cerebral palsy tend to eat soft, easy to swallow foods that are high in carbohydrates. This also tends to make oral clearance of food more difficult with the resultant poor oral hygiene found in most cerebral palsy patients. The patient's inability to control muscle function makes the simple action of tooth brushing difficult. ${ }^{2}$

The slow learner students have the lowest prevalence of caries of $42.86 \%$. Slow-learners are those who fail in schools because of their low intellectual abilities. ${ }^{19}$ About 22 or 23 percent of the population falls into a range that educators label below average or borderline. This means that the child will not learn as easily or as well as his same-age peers. ${ }^{20}$ Hence, they are considered as individuals that fall within the sub category of the retarded. ${ }^{19}$ These children are generally able to maintain an acceptable level of oral hygiene if they are supported by parents or caregivers. ${ }^{21}$ Hence, the lower prevalence of caries amongst this group of students.

Dental caries is a disease with multifactorial causes. The prevalence and incidence of dental caries in a population is influenced by a number of risk factors such as age, sex, ethnic group, dietary patterns and oral hygiene habits. ${ }^{22}$ Other potential factors that may contribute to this difference are the level of parental education and socioeconomic status. ${ }^{23}$

According to the result from Tab. 3, the overall prevalence of caries in the intellectually impaired children at Sekolah Semangat Maju Taiping is $67.86 \%$. A similar research carried out in Hyderabad, India found that the prevalence of caries amongst the mentally challenged children is $56 \%$.

The difference in cultural background may influence the lifestyle and the dietary patterns between these two locations. The samples in Hyderabad study were taken from an institutional centre, whereas the samples from Sekolah Semangat Maju Taiping are living with their families. Those who are very young, those with severe impairments, and those living in institutions are dependent on parents, siblings or caregivers for general care including oral hygiene. Many caregivers do not have the requisite knowledge or values to recognize the importance of oral hygiene and do not themselves practice appropriate oral hygiene or choose a proper diet. A disabled child that resides at home with their parents may be more prone to be pampered with cariogenic food and unhealthy eating habits. ${ }^{24}$

Poor oral health conditions have also been linked to low socio-economic status. Poor and nearly poor children with special health care needs and those with greater limitations attributable to disability were more likely to have unmet dental care needs..$^{24}$ Based on the data obtained on the parent's occupation, the students from Sekolah Semangat Maju Taiping are mostly from the middle to lower socioeconomic status. This could be a possible barrier in terms of access to dental care. Parental or guardian's education background may 
influence the child's oral hygiene maintenance as well. These individual who are responsible for the students might perceive or place a lower importance on dental care. Hence, the child's oral health tends to be neglected and this gives rise to dental caries.

\section{CONCLUSION}

After the research we concluded that the overall prevalence of caries in the intellectually impaired children at Sekolah Semangat Maju Taiping, Perak, Malaysia is $67.89 \%$. Because of their limitations, children with special healtlh care had a poor oral health conditions.

\section{REFERENCES}

1. Ministry of Health Malaysia. 2005. Oral healthcare in Malaysia. [Cited 2008 Nov 10]. http://www.whocollab.od.mah.se/wpro/ malaysia/data/oral_healthcare_in_malaysia_ 05.pdf.

2. Nowak AJ. Dentistry for the handicapped patient. St. Louis: C.V. Mosby Co.; 1976. p. 5-6,35,39-41,108.

3. United nations. Disability-specific instruments. 2003. [cited 2008 Dec 6]. Available from: http://www.un.org/esa/socdev/enable/ rights/wgrefa3.htm\#icf.

4. Allen KE, Marotz L, Batshaw M, Perret $\mathrm{Y}$, Gething, Lindsay et al. Intellectual impairment. 2002. [cited 2009 Nov 5]. Available from: http://www. playcare.unitingchurch.org.au/ intellectual.html.

5. Pinkham JR, Casamassimo PS, Fields JrHW, McTigue DJ, Nowak AJ. Pediatric Dentistry. $4^{\text {th }}$ ed. Philadelphia: W.B. Saunders Co.; 2005. p. 309-10,317-9.

6. Finn SB. Clinical pedodontics. $4^{\text {th }}$ ed. Philadelphia: W.B. Saunder Co.; 2003. p. 530, 562.

7. Welbury RR, Duggal MS, Hosey MT. Paediatric dentistry. $3^{\text {rd }}$ ed. Oxford: Oxford University Press.; 2005. p. 20-2,115-26,133,413-29.

8. Peterson PE. The world oral health report. 2003. [cited 2009 Nov 25]. Available from: http://www.who.int/oral_health/media/en/ orh_report03_en.pdf.

9. Nik-Hussein NN, Muttalib KA, Junid NZ, Wan
Othman WMN, Abang A. Oral health status of 16-year-old school children in Malaysia. Singapore Dent J 2004;26(1):30-8. [cited 2009 Feb 2]. Available from: http: / / health.elsevier. com/ajws_archive/200412261A675.pdf.

10. Bhowate R, Dubey A. Dentofacial changes and oral health status in mentally challenged children. J Indian Soc Pedod Prev Dent 2005;23(2):71-3. [cited 2008 Dec 3]. Available from:http: / / www.jisppd.com/article. asp?issn=0970-4388; year $=2005$; volume $=23$; iss ue $=2$; spage $=71$; epage $=73$; aulast $=$ Bhowate .

11. American Association on Intellectual and Developmental Disabilities. Definition of intellectual disability. 2009. [cited 2008 Feb 18]. Available from: http://www.aaidd.org/ content_100.cfm?navID=21.

12. Roberson TM, Heymann HO, Swift Jr. EJ. Sturdevant's art \& science of operative dentistry. $4^{\text {th }}$ ed. St. Louis: Mosby Inc.; 2002. p. 66-114,274-6.

13. Roth GI, Calmes RB. Oral biology. St. Louis: C.V. Mosby Co.; 1981. p. 282,340-9.

14. American Dental Association. ADA caries risk assessment form completion instructions. 2004. [cited 2009 Mar 10]. Available from: http: / / www.ada.org/prof/resources/topics/ topics_caries_instructions.pdf.

15. Christensen GJ. Special oral hygiene and preventive care for special needs. J Am Dent Assoc 2005;136(8):1141-3. [cited 2009 Mar 28]. Available from: http://jada.ada.org/cgi/ content/full/136/8/1141.

16. National Institute of Dental and Craniofacial Research. 2008. Practical oral care for people with intellectual disabilities. [cited 2009 Mar 28]. Available from: http://www.nidcr.nih. gov/nidcr2.nih.gov/Templates/CommonPage. aspx?NRMODE $=$ Published\&NRNODEGUID $=\{6 \mathrm{~F} 8$ 7D344-D34B-4DA9-9E1C-6E8BC15C1E02\}\&NRO RIGINALURL=\%2fOralHealth\%2fTopics\%2fDeve lopmentalDisabilities\%2fPracticalOralCarePe opleIntellectualDisability.htm\&NRCACHEHINT =Guest\#DentalCaries.

17. Oredugba FA. Oral health condition and treatment needs of a group of Nigerian individuals with Down syndrome. Down syndrome Research and Practice 2007;12(1):7276. [cited 2009 Mar 30]. Available from: http:// www.down-syndrome.org/reports/2022/ 
reports-2022.pdf.

18. Asokan S, Muthu MS, Sivakumar N. Dental caries prevalence and treatment needs of Down syndrome children in Chennai, India. Indian J Dent Res 2008;19(3):224-229. [cited 2009 Mar 30]. Available from: http://www. ijdr.in/article. asp?issn=0970-9290; year $=2008$; volume $=19 ;$ issue $=3$; spage $=224$; epage $=229$; aul ast $=$ Asokan.

19. Sitagita. com. Slow learners. 2009. [cited 2009 Mar 29]. Available from:http://www.sitagita. $\mathrm{com} / \mathrm{view}$. asp?id=531.

20. Warnemuende C. The slow learner. 2009. [cited 2009 Mar 29]. Available from: http: / / www. informedparent.com/article. html?slowlearner.

21. Cawson RA, Odell EW. Cawson's essentials of oral pathology and oral medicine. $7^{\text {th }}$ ed. Philadelphia: Churchill Livingstone; 2002. p. 36-52,362-7.
22. Sudha P, Bhasin S, Anegundi RT. Prevalence of dental caries among 5-13 year old children of Mangalore city. J Indian Soc Pedod Prev Dent 2005;23(2):74-79. [cited 3 Apr 2009]. Available from:http: / / www. jisppd.com / article. asp?issn=0970-4388; year $=2005$; volume $=23$; iss ue $=2$; spage $=74$; epage $=79$; aulast $=$ Sudha .

23. American Academy of Pediatric Dentistry. Policy on use of a caries-risk assessment tool (CAT) for infants, children and adolescents. Pediatric Dent 2006;30(7):29-33. [cited 2009 Apr3].Availablefrom:http://aapd.org/media/ Policies_Guidelines/P_CariesRiskAssess.pdf.

24. Oredugba FA, Akindayomi Y. Oral health status and treatment needs of children and young adults attending a day centre for individuals with special health care needs. BMC Oral Health 2008;8:30. [cited 2009 Mar 30]. Available from: http://www.biomedcentral. com/content/pdf/1472-6831-8-30.pdf. 